\title{
New Facts About Ovarian Stem Cells: The Origin and the Fate
}

\author{
Abbas Majdi Seghinsara ${ }^{1}$, Majid Banimohammad ${ }^{2 *}$
}

\begin{abstract}
Objectives: Infertility is one of the wide-spreading problems that involves $15 \%$ of couples who are in reproductive age. Most of the young couples that suffer from infertility could be cured by means of highly-developed methods and associated reproductive technology (ART). It is important to study about the treatments and methods to improve fertility rate, oogenesis and folliculogenesis. In this study, different types of stem cells which could be used for treatment of infertility would be introduced and discussed.

Evidence Acquisition: Various internet search engines and data bases including Google, Google Scholar, PubMed, Medline, The British Library, and Library of Congress were used.

Results: During the process of puberty, follicles grow and change. Finally they become Graffin follicles. There are various theories about the origin of the follicles and follicular cells. Many diseases or side effects of various therapies (specially the methods that are used in cancer treatment) affect a high range of female patients and cause infertility. The transplantation of exo-ovarian stem cells could be applied in these patients to get advantage of stem cells with non-ovarian derivation. These cells could be used in treatment procedures and in producing new oocytes and follicles. In this study, the role of bone marrow stem cells (BMSCs), mesenchymal stem cells, peripheral blood stem cells (PBSCs), somatic stem cells (SSCs), and ovarian surface epithelium (OSE) are reviewed in treatment of infertility.

Conclusions: The use of stem cells to provide new ovarian reserve or to treat damaged follicles could be successful methods to achieve fertility.

Keywords: Folliculogenesis, Infertility treatment, Ovary, Stem cells
\end{abstract}

\section{Introduction}

Fertility and Infertility in Women

One of the important factors in women fertility, is their ovarian function for ovulation. Follicles as functional units of ovary are made up of oocyte and granulosa cells. In contrast to the continuous gametogenesis in males, formation of female gamete is cyclic, so that ovaries experience an important change every 28 days. Oocyte maturation is dependent on many factors such as genotype of the individual, endocrine glands, estrogen, and progesterone synthesis by granulosa cells. In addition to the factors that mentioned above, oocyte or granulosa cells produce some growth factors (GFs) that affect folliculogenesis.

Infertility is a common problem in which $15 \%$ of couples of reproductive age are involved all around the world. Female infertility could have a variety of reasons such as hypothalamus-pituitary axis malfunction, ovarian factors (polycystic ovary syndrome [PCOS], anovulation, premature menopause), or the uterine tube problems (obstruction of tube or dysfunction of the uterine tubes). However, many young infertile couples could be taken under medical treatment through advanced methods and associated reproductive techniques (ART). It is noteworthy to say that massive efforts should be done in order to enhance the treatment. According to high range of infertility, it would be helpful to study the treatments and methods that would improve fertility rate, oogenesis, and folliculogenesis. One of the most significant and novel methods is utilizing stem cells in the treatment procedure. In this study, after discussing some valuable topics about human ovary and origin of follicles, different types of stem cells which could be used for treatment of infertility would be introduced and discussed.

\section{Evidence Acquisition}

Various internet search engines and data bases including Google, Google Scholar, PubMed, Medline, The British Library and Library of Congress were used to search case reports, case series and review papers on folliculogenesis, infertility of women, treatment methods, and stem cell therapy. Finally, we provided this review article to narrate some valuable topics about human ovary and origin of follicles, the theories, research about this matter, and different types of stem cells which could be used for the treatment of infertility. 


\section{Results and Discussion}

Human Ovary and Ovarian Reserve

According to an old theory, it is believed that ovarian follicles are constant after birth and there is no increase in its level after it. As would be discussed later in detail, this theory has been widely debated in recent years. The theory describes that ovarian follicle and oocyte counts, decrease gradually until menopause: follicle count reaches to the maximum level at 20th week of intra-uterine life (about 7 million); it reaches to 1-2 million at birth, 30000 40000 at puberty, and during reproductive age, it is less than 1000 at menopause (1). The theory claims that about 400 follicles reach to Graffin stage and release the oocyte (2).

\section{Human Ovary and Folliculogenesis}

During the process of puberty, follicles grow and change to primordial follicles, primary follicles, secondary follicles, pre-antral follicles, antral follicles, and finally Graffin follicles. At antral stage, numerous follicles become atretic and just a few of them grow and reach to periovulatory stages. All of process is under the effect of gonadotropins. After the process, under the hormonal and GFs' effects, one of the follicles releases its oocyte and gets ready for fertilization (3). A resting follicle is in primordial stage and histologically oocyte is surrounded by a single flat layer of epithelial cells and a basement membrane. Most of the factors which are the cause of "folliculogenesis development start" and the cause of "change of primordial follicle to primary follicle" remains unknown.

Studies on cattle, monkeys, and humans have demonstrated that in vitro ovarian tissue culture causes a reduction in the inhibition that is present in in vivo condition, and primordial follicles begin their growth to the next levels (4). The change of the morphology of granulosa cells from being flat to cuboid is necessary for follicular growth. Proliferative cell nuclear antigen (PCNA) signals the beginning of proliferation and morphological change of granulosa cells. Two or more layers of granulosa cells surround secondary follicles. When the number of granulosa cell layers reach to 3-6, surrounding stromal cells form theca layer. This layer turns into 2 layers, Internal theca and external theca and blood vessels are created between the 2 layers. During this period of time, the factors involved in folliculogenesis could pass through the blood vessels and induce or inhibit follicular growth (5). When epithelial-like cells are formed in theca interna, follicle enters pre-antral stage, and liquid-filled antrum begin to take form into the follicle. Under the influence of gonadotropins and GFs, follicles get larger, granulosa cells proliferate and are differentiated. Cells close to oocyte are differentiated from Corona radiata. All of these phenomena eventually result in pre-ovulation follicle. Communication between surrounding granulosa cells and oocyte help the growth and the maturation of oocyte and makes it ready for fertilization.
The Origin of the Follicles and Follicular Cells

There are various theories about the origin of the follicles and follicular cells. The oldest theory is "primary or base theory". This theory claims that many mammals have ability to produce a certain number of oocytes which is determined during the embryonic period and each oocyte is surrounded by somatic cells to form follicles $(6,7)$. In recent years, several scientists have claimed that during reproductive age and years after it, there is no increase in the number of oocytes in the ovaries and all the oocytes develop in embryonic period (6). Due to hormonal regulations, a very small number of oocytes in the ovaries have the opportunity to grow and reach their ovulation phase and finally, many of follicles become atretic follicles. The number of available follicles from adolescence to age 50 (menopause), is reduced gradually and ultimately none of them would be available (8). Today, many researchers have accepted the basic theory that claims follicles and oocytes are formed from stem cells during embryonic period and their count remains constant after birth (no follicle formation after birth); however, during the last 150 years, numerous studies have also demonstrated that folliculogenesis occurs after birth.

Waldeyer in 1870 emphasized his opinion that no oocyte and follicles are formed at postnatal period in mammals and birds, and their generation is from ovarian surface epithelium (OSE) or germinal epithelium in the ages before the birth (9). Waldeyer's theory changed by Kingrey a few years later. Kingrey believed that oocytes which are generated in embryologic period would be replaced by oocytes derived from germinal cells later. Allen concurred with the previous theories and added that mitotic divisions in the germinal epithelium produce new oocytes (10). In later years, Pearl and Schoppe noted that there is no increase in the number of oocytes and follicles at postnatal period and endorsed Waldeyer's theory to some extent (11). Discussion and study about the appearance of a new source in mammalian ovary, reached an impasse by Zuckerman (6). However, in later years scientists such as Peters (12) took the theory more practical and showed that oocyte-like cells in the S phase of meiosis II eventually become oocytes if their prenatal growth is completed. These oocytes remain in the ovaries of mice for life and they are used during the fertility period.

However, the basic theory of biology of reproduction in mammals stated that female mammals are born with an assortment of specific and non-renewable oocytes and all of these oocytes are arrested in meiosis I and are enclosed by surrounding cells which called granulosa cells, and form follicles (13-15). Other researchers claimed that, the follicles in the life after birth, gradually decreases and apoptosis is the reduction mechanism $(16,17)$. They purported that ovarian reserve in humans finishes after the 50s and individual inters menopause (18). However, the scientists provided no reason that why the phenomenon of oogenesis in humans stops postnataly, 
but in some animals like Drosophila melanogaster, there is germinal epithelium in the adult ovary and also oogenesis happens (19).

It seems that just few species, mentioned above, are classified in base theory. In one of the species of monkeys, transition stages of oocytes could be seen in different phases of meiosis I, even some of them are considered as germ cells because of standing on very early stages. These cells were also seen in ovaries of young and adult monkeys (20). These findings were confirmed in later years by other scientists, like Ioannon (21). According to this theory, it was believed that in some mammalian species, including humans, ovaries faces an atretic mechanism during fertility and ovarian reserve and gametes remaining from the embryonic period are needed to provide the required oocytes during the reproductive age. Long-time ovarian reserve would cause genetic changes in follicular cells and oocytes by the effects of many genetic and environmental factors on stored oocytes (22).

It is noteworthy that Zuckerman's studies which performed in 1951, left for long periods without an argument and for more than 50 years, his statements had been accepted by other researchers. According to Zuckerman himself, in later years, it became clear that the scientist had no scientific evidence about the inability of ovaries to oogenesis during postnatal period and his statements were just because of the fact that no evidence had been found about postnatally oogenesis in ovaries (23). In recent years, new studies have been conducted and the basic theory has been challenged. They have demonstrated that most reasons of the basic theory, have no scientific basis and they are reviewable and revisable.

In 2003, Hubner et al represented oogenesis in cultured embryonic stem cells. In some studies, germline stem cells (GSCs) had retained their mitotic activity in the ovaries of adult mammals (24). Even mitotic divisions in ovaries of most of them were also shown over the years $(25,26)$.

In a significant study, Bukovsky et al demonstrated that mesenchymal cells in tunica albuginea (TA) have the ability to transform to ovarian epithelial cells. They enter into the ovarian blood vessels and act as germ cells. They are also involved in reformation of follicles in the ovaries of adult women after puberty (27). These findings were of high clinical value and they shook the basis of existing theory about folliculogenesis and oogenesis to a large extent. More research was necessary to construct a stronger scientific basis for new theory. Thus, in recent years, research on the ovary and stem cells has been very challenging. In recent years, Johnson et al (28) presented some evidence about presenting of germ cells and their proliferation in the ovaries of adult mice and also their participation in the ovarian reserve after birth. A study demonstrated that 7 to 100 days after birth, no reduction occurred in the number of primordial follicles in the ovaries of mice. Moreover, it showed that maximum decrease in the number of follicles was after the day 200
(29). The scientists believed that premature germ cells which could be seen in ovaries of adult mammals, have the power to create new oocytes in proper condition. Johnson et al based their claims about the follicle formation and oocytes in post-puberty period on 3 principles:

1. Lack of relationship between atretic follicles and the lost follicles rate in the period before birth,

2. Detection and confirmation of GSCs with high mitotic ability, and

3. The renewal of folliculogenesis in grafted ovaries in samples of adult mice.

According to the role of exo-ovarian stem cells like blood and bone marrow stem cells (BMSCs), in many diseases (such as premature ovarian failure (POF) and infertility in young women caused by chemotherapy and idiopathic infertility), this idea arose that bone marrow and blood cells transplant could be applied in these patients to get help of stem cells with non-ovarian derivation (30). However, this process requires extreme caution because many contaminated cells may be involve the recipient in this process, and the person could likely has an active ovary and fertile oocytes (31).

\section{Follicles Derived From Bone Marrow Stem Cells}

Further studies conducted in recent years proved that a lot of oocytes are quickly produced in the ovaries of adult mice within 24 hours (32). According to the expression of GSC markers in the bone marrow cells, it seems that the bone marrow is an outside source for ovarian stem cells.

Another study conducted on mice, had infertility induced to the mice by undergoing chemotherapy, then bone marrow transplant achieved. It was observed that in addition to the return of fertility in the mice, no genetic problems especially in the oocytes and new follicles occurred (33). These findings could be helpful for people who are deprived of having active ovary and healthy oocytes because of genetic reasons. According to the analysis of gene expression and bone marrow transplantation (BMT) in samples which made infertile by chemotherapy drugs, researchers have demonstrated that there are GSCs in the bone marrow, and when it is necessary, under the appropriate conditions, they provide ovarian reserve for the entire fertility period.

One of the harmful effects of cancer treatment, is damaging of reproductive system. This issue can cause POF and infertility in women younger than 40 years (34-36).

In most cases this is because of toxic effects of chemotherapy drugs on germ cells of ovaries and oocytes. Therefore, when healthy oocytes for fertility are required in women after their chemotherapy, one of the noticeable challenges for researchers is keeping available oocytes and follicles safe in the ovaries during chemotherapy (37-39).

However, women at postmenopausal period who underwent cancer chemotherapy and have received BMT in the treatment of cancer, faced a return in their 
ovarian function for some unknown reasons. They also experienced the beginning of ovarian activity again. In the case of women who were treated with drugs that are cytotoxic for ovary and suffered early menopause, bone marrow transplant returned ovarian activity for some unknown reasons $(40,41)$.

\section{Follicles Derived From Mesenchymal Stem Cells}

Mesenchymal stem cells (MSCs) which are seen in bone marrow culture medium, are multi potency in nature. MSCs have capability of simplicity of separation and culture in larger scales. This matter makes these cells appropriate candidates for stem cell therapy (42). MSCs have been taken into consideration for gene and cellular therapies because of their power of self-renewal and multipotency properties in recent years (43). Direct MSCs transplant into the brain and heart of rats, reduced brain and heart failure following ischemia of the brain and heart $(44,45)$. One of the mechanisms causing this phenomenon is movement of MSCs into the damaged tissues of rat and replacement with damaged cells. However, cytokines that are released from MSCs can repair damaged cells and prevent apoptosis and return their normal function (46).

POF could occur as a result of treatment of childhood cancer with chemotherapy and if the treatment was in late childhood, POF might be remained in adulthood with very high probability.

POF in girls is one of the known problems followed by chemotherapy and radiotherapy and could be observed in $6 \%$ of children after chemotherapy and radiotherapy (47). However, the recovery of ovarian function after cancer treatment in certain cases has been reported in adults and older children.

Rahhal and Eugster reported a case in 2008, in which a patient treated with chemotherapy and radiotherapy was followed by leukemia and growth hormone deficiency. The patient had been exposed to whole-body radiation, which could be a major risk factor in the development of permanent ovarian failure. The patient was subsequently treated with allogeneic umbilical cord blood transplant, 8 years after transplantation. Spontaneous recovery of ovarian function was observed during the patient's puberty (48). Some researchers also demonstrated that ovarian function in the patients who are undergoing chemotherapy, may also be improved by treatment with sexual steroid drugs (49). As mentioned above, new follicles in the ovaries of mice could be generated by GSCs which are derived from bone marrow and entered the bloodstream. The researchers, according to conducted clinical treatments, believed that with blood transfusion alone, we could also achieve top results and infertility could be treated. However, the statements of the researchers about blood transfusion faced with much opposition in later years (50) because Eggan et al believed that, in their research, they had used parabiotic mice in which mouse ovarian have failed to generate new oocytes or follicles after blood transfusion or a bone marrow transplant (51).

According to the results and findings mentioned above, it could be said that one of the reasons for ovarian remission and fertility recovery is re-accumulation of germ cells, or entering of the bloodstream germ cells into the ovary. It is noteworthy that the entry of germ cells of the donor to recipient ovary, could cause social, legal, and very important physiological problems. To clarify this point, in clinical study of Veitia et al, a woman gave birth to a child after allogeneic bone marrow transplant. Despite the clinical status of the patient, who was treated with chemotherapy and radiotherapy, she became pregnant and gave birth to a healthy child (52). Mother's DNA, the child, and the donor were analyzed. Genetic analysis has fully demonstrated that there was no genetic and inheritance relationship between the child and the donor of bone marrow and the child's DNA matched perfectly with the mother's DNA. These findings of Vietia et al, were completely opposed to Johnson's theory which believed that ovarian function remission and fertility recovery are because of the GSCs which enter from bone marrow into ovary (52). It appears that fertility improving after BMT, could be due to reduced degradation of follicles in the ovaries. Notably, according to the other findings, in contrast to radiation therapy, chemotherapy does not cause complete infertility in mice, but chemotherapy keeps some follicles, oocytes, and the GSCs for improvement of ovarian function and renewal after treatment. MSCs transplantation could improve function and structure of damaged tissues. Fu et al conducted a study to investigate the role of MSCs transplantation therapy in ovaries of mice damaged following chemotherapy (53). The researchers demonstrated that damaged ovarian function was improved and granulosa cell apoptosis was reduced. This was the situation in which the chemotherapy drugs were injected in mice after MSCs transplantation. The mechanism of the formation of the above results is maybe due to the role of cytokines released of MSCs after transplantation of these cells and affected ovarian tissue. In a recent study, it is also demonstrated that cytokines are released from the MSCs, in in vitro conditions, cause prevention of granulosa cell apoptosis which can be followed by the toxic effects of chemotherapy drugs (54). After transplantation of MSCs, MSC-derived cells were seen in the ovarian tissue but did not exist inside the follicles. These findings indicate that MSCs may have an important role in the protection and promotion of the ovary. However, is doubtful that MSCs differentiate to granulosa cells or oocytes (55).

Recent studies have caused many challenges about fertility, growth, and differentiation of GSCs. Many researchers in recent years have indicated that in in vitro condition, stem cells derived from embryonic stem cells, or teratocarcinoma stem cells could differentiate to GSCs, but in the condition that a suitable environment is provided in the testes or ovaries for it $(56,57)$. 
Follicles Derived From Peripheral Blood Stem Cells Similar studies conducted by other scientists and demonstrated that peripheral blood $(\mathrm{PB})$ is also another source of GSCs in the ovaries of adult mice. After transgenic-mice blood transfusion through which their cells were labeled with green fluorescent protein (GFP), infertile recipient mice produced oocytes with positive GFP and were seen in primordial follicles in ovaries of receiver mice (56).

The above findings demonstrated that germ cells (germline germ cells) existing in bone marrow, are released in $\mathrm{PB}$ and come to the ovary by blood and are replaced there (33).

\section{Follicles Derived From Somatic Stem Cells}

Ovary contains many inactive primordial follicles. Each follicle contains a small non-grown oocyte and a layer of amorphous cells which are surrounded by follicular basement membrane (57). In a portion of the physiological process, primordial follicles activate and oocytes begin to grow. The surrounding granulosa cells start mitotic divisions. With their mitotic divisions, the number of granulosa cell layers which surround oocyte, begins to increase and basement membrane expands (57).

Primordial follicles grow and evolve to primary follicles and they are also change to preantral follicles (secondary), antral (tertiary), eventually preovulatory, and Graffin follicles. It seems that stem cells of granulosa cells are also capable of producing follicles. All these phenomena are regulated by hormones and environmental factors inside the ovary and have a significant impact on promoting this process (58). The role of granulosa cells known as somatic cells is critical.

Follicles Derived From Ovarian Surface Epithelium In adults, it seems that OSE is a new source for germ cells and primary follicles which are created because of placement of granulosa cells and oocyte in the ovary cortex together. Some studies have demonstrated that, in the medium, oocytes and granulosa cells arise from ovary surface epithelium and these events are possible in in vitro conditions. Cells were cultured under appropriate conditions and were represented phenotype of normal oocytes. The obtained oocytes also displayed other conditions including the creation of polar body and expression of genes related to secondary oocytes. Create primary follicles in vitro conditions could be the reason for existence of another source of oocytes and granulosa cells $(59,60)$.

According to renewal of folliculogenesis and generating new follicles in the ovaries of adult women, many studies have demonstrated that the OSE could be a new source for oocytes and granulosa cells which primary follicles arise by juxtapositioning of them in ovarian cortex. It is believed that the components of a new primary follicle, the granulosa cells and germ cells, differentiate among mesenchymal progenitor cells in TA layer of ovary.

In the phenomenon of differentiation, mesenchymal cells of TA enter into the OSE or its crypts. Mesenchymal cells are then gotten the characteristics of epithelial cells, and it seems that they are progressing to produce somatic cells (granulosa cells). Epithelial cells generated by mesenchymal cells, make a cord-mode structure and drop to deeper parts of the ovarian cortex. These cells could be a source of germ cells that along with granulosa cells which are created in the OSE, could be sufficient to create new primary follicles. Oogenesis occurs after these events (59).

The theory that new primary follicles originate form OSE and source of germ cells is in this layer of the ovary, is inconsistent with statements of Johnson et al to some extent. It is because that they believed that the source of germ cells and granulosa Cells are in the bone marrow and new follicles are created by their release to $\mathrm{PB}$ and replacement in ovary (61). It seems that Bukovsky theory be more correct. In older women, oocytes and follicles undergo genetic changes for any reason including genetic and environmental factors. This is because of the fact that in older women, OSE loses its morphology and may not be able to supply needed germ cells and stem cells to create new follicles.

Approximately, most of researchers agree that infertility is a noticeable matter which could have different causes from PCOS to hormonal disorders. The PCOS is one of the most common causes of anovulatory infertility and a notable number of women in reproductive age are affected by it. It even could be a risk factor for cancer development (62). Hormonal disorders are also possible candidates for infertility. The hope of stem cell therapy grows day by day and maybe become the major treatment for infertility.

\section{Conclusions}

Nowadays, it is undeniable that stem cell therapy and the use of multi-potent cells in the treatment procedure of women infertility is one of the most significant debates. The use of stem cells to provide new ovarian reserve or to treat damaged follicles could be safe and successful methods to achieve fertility. Bone marrow stem cells (BMSC), MSCs (MSC), peripheral blood stem cells (PBSC), somatic stem cells (SSC), and OSE could be some sources for stem cells. Finally, there are many researches that confirm this matter.

\section{Conflict of Interests}

Authors declare that they have no conflict of interests.

\section{Ethical Issues}

We have no ethical issues to declare.

\section{Financial Support}

None to be declared. 


\section{References}

1. Faddy MJ. Follicle dynamics during ovarian ageing. Mol Cell Endocrinol. 2000;163(1-2):43-48.

2. Gougeon A. Régénération des ovocytes : fantasme ou réalité ? Gynecol Obstet Fertil. 2005;33(10):819-823. doi:10.1016/j. gyobfe.2005.07.029

3. McClellan KA, Gosden R, Taketo T. Continuous loss of oocytes throughout meiotic prophase in the normal mouse ovary. Dev Biol. 2003;258(2):334-348. doi:10.1016/S00121606(03)00132-5

4. Wagers AJ, Weissman IL. Plasticity of adult stem cells. Cell. 2004;116(5):639-648.

5. Rodgers RJ, Lavranos TC, van Wezel IL, Irving-Rodgers HF. Development of the ovarian follicular epithelium. Mol Cell Endocrinol. 1999;151(1-2):171-179.

6. Zuckerman S. The number of oocytes in the mature ovary. Recent Prog Horm Res. 1951;6:63-109.

7. Burkl W, Schiechl H. The growth of follicles in the rat ovary under the influence of busulphan and endoxan. Cell Tissue Res. 1978;186(2):351-359.

8. Richardson SJ, Senikas V, Nelson JF. Follicular depletion during the menopausal transition: evidence for accelerated loss and ultimate exhaustion. J Clin Endocrinol Metab. 1987;65(6):1231-1237. doi:10.1210/jcem-65-6-1231

9. Waldeyer W. Eierstock und Ei. Engelmann, Leipzig; 1870.

10. Allen E. Ovogenesis during sexual maturity. Am J Anat. 1923;31(5):439-481. doi:10.1002/aja.1000310502

11. Pearl R, SchoppeWF. Studies on the physiology of reproduction. J Clin Endocrinol Metab. 2010;32:485-499.

12. Peters H. Migration of gonocytes into the mammalian gonad and their differentiation. Philos Trans R Soc Lond B Biol Sci. 1970;259(828):91-101.

13. Borum K. Oogenesis in the mouse. A study of the meiotic prophase. Exp Cell Res. 1961;24:495-507.

14. McLaren A. Meiosis and differentiation of mouse germ cells. Symp Soc Exp Biol. 1984;38:7-23.

15. Anderson LD, Hirshfield AN. An overview of follicular development in the ovary: from embryo to the fertilized ovum in vitro. Md Med J. 1992;41(7):614-620.

16. Perez GI, Robles R, Knudson CM, Flaws JA, Korsmeyer SJ, Tilly JL. Prolongation of ovarian lifespan into advanced chronological age by Bax-deficiency. Nat Genet. 1999;21(2):200-203. doi:10.1038/5985

17. Tilly JL, Johnson J. Recent arguments against germ cell renewal in the adult human ovary: is an absence of marker gene expression really acceptable evidence of an absence of oogenesis? Cell Cycle. 2007;6(8):879-883. doi:10.4161/ cc.6.8.4185

18. Richardson MC, Slack C, Stewart IJ. Rearrangement of extracellular matrix during cluster formation by human luteinising granulosa cells in culture. J Anat. 2000;196 ( Pt 2):243-248.

19. Deng W, Lin H. Asymmetric germ cell division and oocyte determination during Drosophila oogenesis. Int Rev Cytol. 2001;203:93-138.

20. Bapat SA, Mali AM, Koppikar CB, Kurrey NK. Stem and progenitor-like cells contribute to the aggressive behavior of human epithelial ovarian cancer. Cancer Res. 2005;65(8):3025-3029. doi:10.1158/0008-5472.can-04-3931

21. Ioannou JM. Oogenesis in adult prosimians. J Embryol Exp Morphol. 1967;17(1):139-145.

22. Bukovsky A, Caudle MR, Svetlikova M, Wimalasena J, Ayala ME, Dominguez R. Oogenesis in adult mammals, including humans: a review. Endocrine. 2005;26(3):301316. doi:10.1385/endo:26:3:301

23. Zuckerman S. Beyond the Ivory Tower: The Frontiers of Public and Private science. Taplinger Pub. Co;1971:22-34.

24. Hubner K, Fuhrmann G, Christenson LK, et al. Derivation of oocytes from mouse embryonic stem cells. Science. 2003;300(5623):1251-1256. doi:10.1126/science.1083452

25. Irving-Rodgers HF, Rodgers RJ. Extracellular matrix of the developing ovarian follicle. Semin Reprod Med. 2006;24(4):195-203. doi:10.1055/s-2006-948549

26. Johnson J, Canning J, Kaneko T, Pru JK, Tilly JL. Germline stem cells and follicular renewal in the postnatal mammalian ovary. Nature. 2004;428(6979):145-150. doi:10.1038/nature02316

27. Bukovsky A, Svetlikova M, Caudle MR. Oogenesis in cultures derived from adult human ovaries. Reprod Biol Endocrinol. 2005;3:17. doi:10.1186/1477-7827-3-17

28. Johnson J, Skaznik-Wikiel M, Lee HJ, Niikura Y, Tilly JC, Tilly JL. Setting the record straight on data supporting postnatal oogenesis in female mammals. Cell Cycle. 2005;4(11):1471-1477. doi:10.4161/cc.4.11.2186

29. Kerr JB, Duckett R, Myers M, Britt KL, Mladenovska T, Findlay JK. Quantification of healthy follicles in the neonatal and adult mouse ovary: evidence for maintenance of primordial follicle supply. Reproduction. 2006;132(1):95109. doi:10.1530/rep.1.01128

30. Johnson J, Bagley J, Skaznik-Wikiel M, et al. Oocyte generation in adult mammalian ovaries by putative germ cells in bone marrow and peripheral blood. Cell. 2005;122(2):303-315. doi:10.1016/j.cell.2005.06.031

31. Frank O, Heim M, Jakob M, et al. Real-time quantitative RT-PCR analysis of human bone marrow stromal cells during osteogenic differentiation in vitro. J Cell Biochem. 2002;85(4):737-746. doi:10.1002/jcb.10174

32. Greenfeld C, Flaws JA. Renewed debate over postnatal oogenesis in the mammalian ovary. Bioessays. 2004;26(8):829-832. doi:10.1002/bies.20094

33. Krause DS. Engraftment of bone marrow-derived epithelial cells. Ann N Y Acad Sci. 2005;1044:117-124. doi:10.1196/ annals.1349.015

34. Meirow D, Nugent D. The effects of radiotherapy and chemotherapy on female reproduction. Hum Reprod Update. 2001;7(6):535-543.

35. Wenzel L, Dogan-Ates A, Habbal R, et al. Defining and measuring reproductive concerns of female cancer survivors. J Natl Cancer Inst Monogr. 2005(34):94-98. doi:10.1093/jncimonographs/lgi017

36. Lee SJ, Schover LR, Partridge AH, et al. American Society of Clinical Oncology recommendations on fertility preservation in cancer patients. J Clin Oncol. 2006;24(18):2917-2931. doi:10.1200/jco.2006.06.5888

37. Tilly JL. Commuting the death sentence: how oocytes strive to survive. Nat Rev Mol Cell Biol. 2001;2(11):838-848. doi:10.1038/35099086

38. Paris F, Perez GI, Fuks Z, et al. Sphingosine 1-phosphate preserves fertility in irradiated female mice without propagating genomic damage in offspring. Nat Med. 2002;8(9):901-902. doi:10.1038/nm0902-901

39. Lee HJ, Selesniemi K, Niikura Y, et al. Bone marrow transplantation generates immature oocytes and rescues long-term fertility in a preclinical mouse model of chemotherapy-induced premature ovarian failure. J Clin Oncol. 2007;25(22):3198-3204. doi:10.1200/ 
jco.2006.10.3028

40. Scintu F, Reali C, Pillai R, et al. Differentiation of human bone marrow stem cells into cells with a neural phenotype: diverse effects of two specific treatments. BMC Neurosci. 2006;7:14. doi:10.1186/1471-2202-7-14

41. Hershlag A, Schuster MW. Return of fertility after autologous stem cell transplantation. Fertil Steril. 2002;77(2):419-421.

42. Fu X, Fang L, Li X, Cheng B, Sheng Z. Enhanced woundhealing quality with bone marrow mesenchymal stem cells autografting after skin injury. Wound Repair Regen. 2006;14(3):325-335. doi:10.1111/j.1743-6109.2006.00128.x

43. Portmann-Lanz CB, Schoeberlein A, Huber A, et al. Placental mesenchymal stem cells as potential autologous graft for pre- and perinatal neuroregeneration. Am J Obstet Gynecol. 2006;194(3):664-673. doi:10.1016/j. ajog.2006.01.101

44. Li Y, Chopp M, Chen J, et al. Intrastriatal transplantation of bone marrow nonhematopoietic cells improves functional recovery after stroke in adult mice. J Cereb Blood Flow Metab. 2000;20(9):1311-1319. doi:10.1097/00004647200009000-00006

45. Orlic D, Kajstura J, Chimenti S, et al. Bone marrow cells regenerate infarcted myocardium. Nature. 2001;410(6829):701-705. doi:10.1038/35070587

46. Xu M, Uemura R, Dai Y, Wang Y, Pasha Z, Ashraf M. In vitro and in vivo effects of bone marrow stem cells on cardiac structure and function. J Mol Cell Cardiol. 2007;42(2):441448. doi:10.1016/j.yjmcc.2006.10.009

47. Chemaitilly W, Mertens AC, Mitby P, et al. Acute ovarian failure in the childhood cancer survivor study. J Clin Endocrinol Metab. 2006;91(5):1723-1728. doi:10.1210/ jc. 2006-0020

48. Rahhal SN, Eugster EA. Unexpected recovery of ovarian function many years after bone marrow transplantation. J Pediatr. 2008;152(2):289-290. doi:10.1016/j. jpeds.2007.10.052

49. Oktay K. Spontaneous conceptions and live birth after heterotopic ovarian transplantation: is there a germline stem cell connection? Hum Reprod. 2006;21(6):1345-1348. doi:10.1093/humrep/del007

50. Telfer EE, Gosden RG, Byskov AG, et al. On regenerating the ovary and generating controversy. Cell. 2005;122(6):821822. doi:10.1016/j.cell.2005.09.004

51. Eggan K, Jurga S, Gosden R, Min IM, Wagers AJ. Ovulated oocytes in adult mice derive from non-circulating germ cells. Nature. 2006;441(7097):1109-1114. doi:10.1038/ nature04929

52. Veitia RA, Gluckman E, Fellous M, Soulier J. Recovery of female fertility after chemotherapy, irradiation, and bone marrow allograft: further evidence against massive oocyte regeneration by bone marrow-derived germline stem cells. Stem Cells. 2007;25(5):1334-1335. doi:10.1634/ stemcells.2006-0770

53. Fu X, He Y, Xie C, Liu W. Bone marrow mesenchymal stem cell transplantation improves ovarian function and structure in rats with chemotherapy-induced ovarian damage. Cytotherapy. 2008;10(4):353-363. doi:10.1080/14653240802035926

54. Geijsen N, Horoschak M, Kim K, Gribnau J, Eggan K, Daley GQ. Derivation of embryonic germ cells and male gametes from embryonic stem cells. Nature. 2004;427(6970):148154. doi: $10.1038 /$ nature 02247

55. Vigo D, Villani S, Faustini M, et al. Follicle-like model by granulosa cell encapsulation in a barium alginateprotamine membrane. Tissue Eng. 2005;11(5-6):709-714. doi:10.1089/ten.2005.11.709

56. Lacham-Kaplan O, Chy H, Trounson A. Testicular cell conditioned medium supports differentiation of embryonic stem cells into ovarian structures containing oocytes. Stem Cells. 2006;24(2):266-273. doi:10.1634/stemcells.2005-0204

57. Grove JE, Bruscia E, Krause DS. Plasticity of bone marrowderived stem cells. Stem Cells. 2004;22(4):487-500. doi:10.1634/stemcells.22-4-487

58. Vogel G. Reproductive biology. Controversial study finds an unexpected source of oocytes. Science. 2005;309(5735):678679. doi:10.1126/science.309.5735.678

59. Bukovsky A, Keenan JA, Caudle MR, Wimalasena J, Upadhyaya NB, Van Meter SE. Immunohistochemical studies of the adult human ovary: possible contribution of immune and epithelial factors to folliculogenesis. Am J Reprod Immunol. 1995;33(4):323-340.

60. Abedelahi A. Differentiation of Human Ovarian Surface Epithelial (OSE) Stem Cells into Primary Follicles. Jokull J. 2014;64(2):133-149. doi:10.13140/RG.2.1.4788.6888

61. Bukovsky A, Caudle MR, Svetlikova M, Upadhyaya NB. Origin of germ cells and formation of new primary follicles in adult human ovaries. Reprod Biol Endocrinol. 2004;2:20. doi:10.1186/1477-7827-2-20

62. Bani Mohammad M, Majdi Seghinsara A. Polycystic Ovary Syndrome (PCOS), Diagnostic Criteria, and AMH. Asian Pac J Cancer Prev. 2017;18(1):17-21. doi:10.22034/ apjcp.2017.18.1.17

(C) 2018 The Author (s); This is an open-access article distributed under the terms of the Creative Commons Attribution License (http://creativecommons.org/licenses/by/4.0), which permits unrestricted use, distribution, and reproduction in any medium, provided the original work is properly cited. 